\title{
Review on Characterization and Mechanical Performance of Self-cleaning Concrete
}

\author{
Siti Norsaffirah Zailan ${ }^{1,{ }^{*}}$, Norsuria Mahmed ${ }^{1}$, Mohd Mustafa Al Bakri Abdullah ${ }^{1}$, Andrei \\ Victor Sandu ${ }^{3}$, and Noor Fifinatasha Shahedan ${ }^{1}$ \\ ${ }^{1}$ Centre of Excellence Geopolymer and Green Technology (CEGeoGTech), School of Materials \\ Engineering, Universiti Malaysia Perlis (UniMAP), 01007, P. O Box 77, D/A Pejabat Pos Besar, \\ Kangar, Perlis, Malaysia \\ ${ }^{2}$ Faculty of Engineering Technology, Universiti Malaysia Perlis (UniMAP), P. O Box 77, D/A Pejabat \\ Pos Besar, Kangar, Perlis 01000, Malaysia \\ ${ }^{3}$ Gheorghe Asachi Technical University, Faculty of Materials Science and Engineering, D. 61A \\ Mangeron Str., 700050, lasi, Romania
}

\begin{abstract}
Self-cleaning concrete is an effective alternative to provide cleaner environment which contribute to sustainability and towards a green environment. It is in accordance with the requirements of environmental issues on huge energy consumption and air pollution from carbon dioxide $(\mathrm{CO} 2)$ emissions. Photocatalyst in self-cleaning concrete accelerates the decomposition of organic particulates, hence pollution could be reduced through photocatalytic degradation of gaseous pollutants. Mechanical performances of self-cleaning concrete were improved by adding photocatalytic materials. Self cleaning abilities were evaluated in the photocatalytic activity test under UV light and photocatalytic degradation of gaseous pollutant was measured by depollution test. This review aims to give an overview about the characteristics of photocatalytic materials and mechanical performances of self-cleaning concrete.
\end{abstract}

\section{Introduction}

The demand usage of concrete increases as cities grow. However, the utilization of concrete causes pollution to the environment, hence give negative impacts on the environment. Quality of air becomes an important issue for public health and the environment. Thus, recently, many research having a great concern in the development of cementless concrete in order to reduce $\mathrm{CO}_{2}$ emission that caused by concrete dust [1]. Geopolymer concrete with self-cleaning behavior is an innovative construction material that had been introduced to reduce this problem. In geopolymer concrete, the role of the binder is replaced by fly ash, which is cementitious materials as ordinary Portland cement (OPC) due to high content of alumina and silicate, whereas alkaline solution act as an activator which is a combination of sodium hydroxide $(\mathrm{NaOH})$ and sodium silicate $\left(\mathrm{Na}_{2} \mathrm{SiO}_{3}\right)$ [2].

Self-cleaning concrete has an ability to clean their surfaces by itself. Self-cleaning technology has been derived from nature. The surface of self-cleaning inspired by the

\footnotetext{
* Corresponding author: sitinorsaffirah@yahoo.com
} 
nanostructures of a lotus leaf which based on superhydrophobic effect, which residues are washed off by rain, thus carrying away dirt and debris. This is due to the photocatalytic actions with the addition of photocatalyst onto the concrete [3]. Photocatalytic reaction uses the energy from ultraviolet rays to oxidize organic compounds. This reaction is able to accelerate the process of natural oxidation and faster pollutant decomposition. Photocatalytic have two primary benefits which are kept surface free of dirt and ensure a cleaner environment. Photocatalytic materials is not only apart, having a wide range of applications, but it also offers various benefits, which include reduction in maintenance cost and time (process of cleaning), thereby energy was saved in cooling the buildings by reducing the temperature [4].

Previous research reported about the presence of voids in concrete, which is about $1-2 \%$ that leads to decrement of compressive strength [5]. Thus, nanoparticles photocatalyst would fill the voids between cement particles, then smaller pores are produced in order to increase the strength, modify the properties and improve durability, thermal, mechanical, and electrical properties of cementitious materials. Nanoparticles are commonly used in the research as photocatalyst is silicon oxide $\left(\mathrm{SiO}_{2}\right)$, zinc oxide $(\mathrm{ZnO})$, aluminium oxide $\left(\mathrm{Al}_{2} \mathrm{O}_{3}\right)$ and titanium oxide $\left(\mathrm{TiO}_{2}\right)$ [5]. In the previous study [6], concrete containing of titanium dioxide with white cement are prepared, while titanium dioxide is added in relatively small amounts of cement and was doped with silver $(\mathrm{Ag})$ to improve the early resistance of the concrete. Many research activities are currently conducted about applications of nano materials on construction materials. Recently nano silica (nano- $\mathrm{SiO}_{2}$ ) and nano titanium (nano- $\mathrm{TiO}_{2}$ ) are reported that can improve the mechanical properties of mechanical and durability properties of concrete which causes an improvement of the refined porous structure of concrete, whereas resistance to chloride penetration increased [7].

\section{Processing of Self-cleaning concrete}

Mix Design. The study of fly ash and photocatalyst was mixed in different proportions and used to produce self-cleaning concrete. Recently in the previous experiments [5], nano- $\mathrm{TiO}_{2}$ powder was used as the photocatalyst, while OPC and white ordinary Portland cement were used as the cementitious materials which act as a binder. $\mathrm{TiO}_{2}$-modified cement are made of ordinary white cement, water and different contents of $\mathrm{TiO}_{2}$ nanoparticles $(0 \%, 0.5 \%, 1 \%$, $1.5 \%, 2 \%, 2.5 \%$ and $3 \%$ ) for self-cleaning and testing for setting time. Other than that, sand with standard size was added for compressive and flexural strength tests. The same method was practice of another reported research [8], where there only differs in step of addition the nanoparticles onto the modified concrete. The samples dispersed $\mathrm{TiO}_{2}$ powder in ethanol followed by ultrasonic vibration for $15 \mathrm{~min}$ for TEM observations.

Other research reported that, the crude titanium dioxide was later added to the cement powder in the preparation process of the cement plates [9]. Previous researchers state that, ordinary Portland cement and fly ash class F (low calcium fly ash) were used as the cementitious materials to produce geopolymer concrete. The amount of fly ash used was $25 \%$ from weight of cement. Other than that, natural river sand was used as fine aggregate and were washed before using it. Cement, water, sand and fly ash were mixed at binder ratio 0.4 . The amount of photocatalyst in the mixture was varied with ratios of $1 \%, 3 \%$ and $5 \%$ of the cement weight and all mixtures (single, binary and ternary) are remaining constant [10].

Mixing Process. W. Shen et al. [8] proposed mixing cement with various nano particles $\mathrm{TiO}_{2}$ contents $(0 \%, 2.5 \%, 5.0 \%$ and $7.5 \%)$ by using a ball mill with a diameter of $500 \mathrm{~mm}$ for 30 min. Besides that, other researchers who have used $\mathrm{TiO}_{2}$ as photocatalyst in their study was added powdered $\mathrm{TiO}_{2}$ to the dry cement before mixing, then subsequent water was added. Then, cementitious paste was mechanically stirred at $140 \mathrm{rpm}$ with 62 planetary motions per minute for $30 \mathrm{~s}$. The paste are then will be cast into molds with dimension 8.6 
$\mathrm{cm}$-diameter Petri dish. The duration for curing process are 24 hours and was placed at room temperature at $20^{\circ} \mathrm{C}$ under $70 \%$ relative humidity (RH) and, $100 \% \mathrm{RH}$ for the next 27 days. Before the characterization and the photocatalytic tests were conducted, samples were aged at least three months [11].

The same method of mixing was applied by D. Feng et. $A l[12]$ but the $\mathrm{TiO}_{2}$ nanoparticles and cement were soaked in water and vibrated ultrasonically for $30 \mathrm{~min}$ in order to achieve better distribution before mixing process. On the other hand, P. Duan et. al [13] reported that the purpose of vibration is to remove the entrained air bubbles. However, other researchers [9] have stated that the different amount of ratio were added to raw cement and mixed mechanically by using porcelain mortar which are then be cast in silicone mold $(20 \mathrm{~mm} \times 20$ $\mathrm{mm} \times 6 \mathrm{~mm}$ ) and curing for 28 days at room temperature. Then, homogenous powders that obtained were mixed with water (water-to-cement ratio $\mathrm{w} / \mathrm{c}=0.48$ ). The author believes that excessive additional of water will creates additional voids which known as capillary pores and give a big influence on the strength and permeability of the concrete.

\section{Characterization materials in self-cleaning concrete}

X-ray Fluorescence (XRF). Previous research has studied about the characteristics of the raw materials that use in geopolymer concrete by using X-ray Fluorescence (XRF). Based on the chemical composition, these previous raw materials that have been used in geopolymer concrete contain high content in Silica (Si), Alumina (Al), Calcium (Ca) and Ferum (Fe) which indicates the performance of geopolymer materials are good enough to be applied as cementitious materials [13]. According to M. Mustafa et al. [14], fly ash that commonly used as a binder in current research have two types, which are Class $\mathrm{C}$ (high calcium fly ash) and Class $\mathrm{F}$ (low calcium fly ash). Fly ash are categorized under class $\mathrm{C}$ type if the composition analysis of $\mathrm{CaO}$ content are more than $10 \%$, while class $\mathrm{F}$ type of fly ash which contain less than $10 \%$ of the $\mathrm{CaO}$. Fly ash class $\mathrm{C}$ type are commonly being used as replacement of cement in construction materials.

X-ray Diffraction (XRD). Previous published research has studied the characterization of raw material $\left(\mathrm{TiO}_{2}\right)$ that has been used as a photocatalytic application by using X-ray Diffraction (XRD) [15]. According to P. Krishnan et al. [15], crystal structure deterioration is a possible reason for the efficiency for photocatalytic of titania to decrease. However, the XRD patterns before and after 400 hours of UV exposure demonstrates stability of the $\mathrm{TiO}_{2}$ crystal structure due to nearly identical of $\mathrm{TiO}_{2}$ photocatalyst. The author suggests that the deterioration of crystal structure would not occur within the investigated duration because it may cause decreased photocatalysis of $\mathrm{TiO}_{2}$.

According to previous research has found that XRD pattern measured for raw cement had no impact on the phase composition. The published research revealed that the presence of additional peaks which assigned to the anatase and rutile phases when Titania photocatalyst was added to the raw cement [9]. The narrower anatase peak indicates higher crystallinity that occurred in photocatalyst. Additionally, it was applied in high temperature of calcination which caused a partial phase transformation from anatase to rutile.

Scanning Electron Microscopy (SEM). According to Hui $\mathrm{Li}$ et. al [16], the microstructures between the cement mortar mixed with the nano-particles and the plain cement mortar are observed by Scanning Electron Microscope (SEM). The result showed that the pores was filled up with nano- $\mathrm{Fe}_{2} \mathrm{O}_{3}$ and nano- $\mathrm{SiO}_{2}$ and the $\mathrm{Ca}(\mathrm{OH})_{2}$ compound are reduced between the hydrate. From the SEM observation, nano-particles also act as activator either than filler in order to improve the microstructure of the cement paste, where nano-particles were spread uniformly.

Another research [6] reported that, surface of prepared cement samples were analyzed using SEM as shown in Figure 1. SEM images obviously show the surface of pure white 
cement particle were closely packed while even distributions of $\mathrm{TiO}_{2}$ are highlighted in circles on the surface of the sample cement slab with $\mathrm{TiO}_{2}$ which have a ratio 0.1 and 0.2 . The photocatalyst are well distributed on the surface. The author also reported that there is some dust and small cracks are being observed on the surface of pure cement. However, P. Duan et al.[13] reported that the addition of nano- $\mathrm{TiO}_{2}$ enhances the geopolymer formation and microstructures become denser with fewer crack.

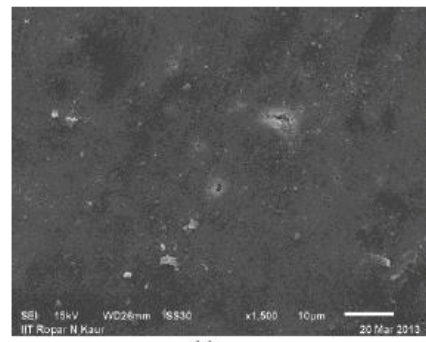

(a)

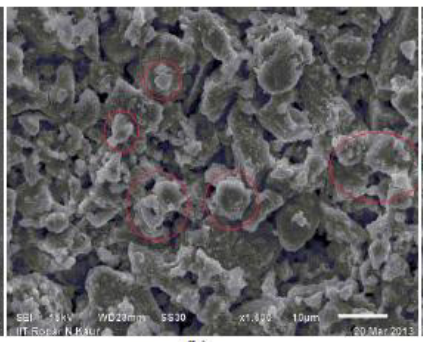

(b)

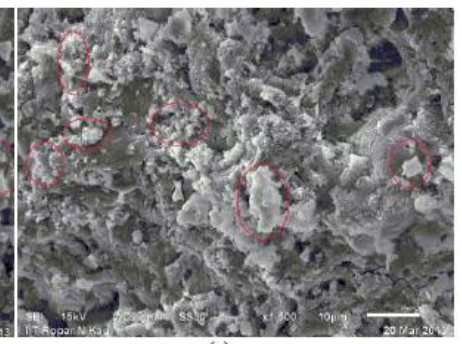

(c)

Fig. 1. SEM images at 1500x of (a) Cement slab made up of white cement only (b) Cement slab made-up of $\mathrm{TiO} 2$ to white cement ratio of 0.1 (c) Cement slab made-up of $\mathrm{TiO} 2$ to white cement ratio of $0.2[6]$

\section{Mechanical properties on self-cleaning concrete}

Compressive Strength. Previous research that study on the mechanical properties $\mathrm{TiO}_{2}$-modified cementitious materials state that the partial addition of $\mathrm{TiO}_{2}$ nanoparticles into cement improved the mechanical properties of the cement mortar [5]. On the other hand, compressive strength increases with increasing the amount of $\mathrm{TiO}_{2}$ nanoparticles by $1 \%$. This is because pozzolanic activity of $\mathrm{TiO}_{2}$ in hydrating cement attributed to the improvement of compressive strength of the modified concrete. There is a research on the effect of nanomaterials as cement replacement on physical properties of concrete, reported that the compressive strength of concrete and cement by using various nano products that commonly used in published research as additives and admixtures was reduced as in Table 1 [17].

From the other reported research on the mechanical properties, state that compressive strength increase up to $1 \%$ replacement of cement by $\mathrm{TiO}_{2}$. The main reason increasing of compressive strength is because of voids of mortar was filled with small size titanium dioxide, which leads to increase the strength. In addition, the cement particles covered by the excess amount of $\mathrm{TiO}_{2}$ which disrupts the water cement reaction, hence the decrease the strength on further increment. As in Figure 2 shows a comparison of compressive strength with the replacement of cement by titanium dioxide $(1 \%, 2 \%, 3 \%)$ that cured in 28 days. The author suggests to extend this study on various properties of concrete by changing the particle size of titanium dioxide and various grades of concrete [10]. 
Table 1. Compressive strength test of cement cube (MPa) [17]

\begin{tabular}{|c|c|c|c|c|}
\hline Days & $\begin{array}{c}\text { Normal } \\
\text { Concrete } \\
\text { Mortar }\end{array}$ & $\begin{array}{c}\text { Nano Alumina } \\
\text { Mortar }\end{array}$ & $\begin{array}{c}\text { Nano Titania } \\
\text { Mortar }\end{array}$ & $\begin{array}{c}\text { Nano Silica } \\
\text { Mortar }\end{array}$ \\
\hline 7 & 22.069 & 16.050 & 12.049 & 7.356 \\
\hline 14 & 32.102 & 20.731 & 18.725 & 16.719 \\
\hline
\end{tabular}

\section{Variation in compressive strength}

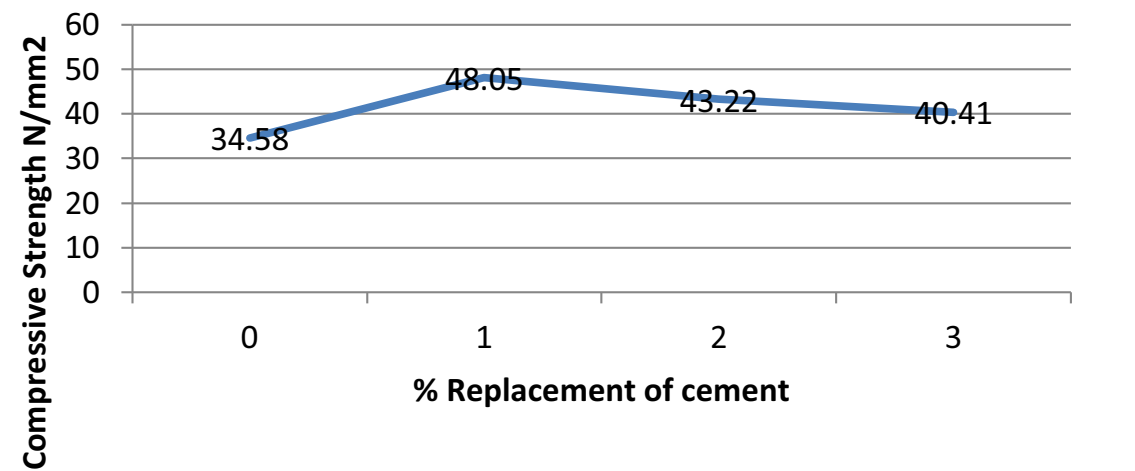

Fig. 2. Comparison of compressive strength with the replacement of cement by titanium dioxide (Days 28) [10]

Flexural Strength. From the previous research, flexural strength is conducted for measurement of the tensile strength of the concrete to resist failure in bending [5]. It was reported that the increases of flexural strength with increasing the amount of $\mathrm{TiO}_{2}$ nanoparticles up to $1 \%$ due to the reaction between $\mathrm{TiO}_{2}$ nanoparticles and calcium hydroxide are fast. These reactions were made in the cement hydration in order to form the denser structure. Published research that study on the compressive, tensile and flexural strength of cement mortar containing nanoparticles state that the mechanical properties of $\mathrm{Al}_{2} \mathrm{O}_{3}$ nanoparticles $(1 \%$ and $3 \%)$ are better than ordinary cement mortar [7]. The results of flexural strength are lower than compressive strength results. However, the results with the addition of photocatalytic materials (nano- $\mathrm{TiO}_{2}$ and nano- $\mathrm{SiO}_{2}$ ) are less significant increased.

\section{Self-cleaning test}

Photocatalytic testing. A self-cleaning test was conducted to assess the abilities of self-cleaning of the material. Previous research reported that photo degradation of methylene 
blue (MB) solution was studied in order to evaluate the photocatalytic properties of self-cleaning on the surface of concrete under UV radiation. As shown in Figure 3, the color of the solution indicates a photocatalytic effect of self-cleaning concrete on the degradation of MB blue with different percentage of Titania as photocalyst by exposing time. The concrete with high content of $\mathrm{TiO}_{2}$ has obvious effect on the degradation of $\mathrm{MB}$ blue, which has a higher degradation ratio than the lower $\mathrm{TiO}_{2}$ content. This shows that nano- $\mathrm{TiO}_{2}$ particles have the potential for as a photocatalyst for building materials [8]. Other than the degradation of $\mathrm{MB}$, there are other published research reported that performances of self-cleaning mortars were verified by monitoring the discoloration of organic dyes (Rhodamine B (RhB) [18].

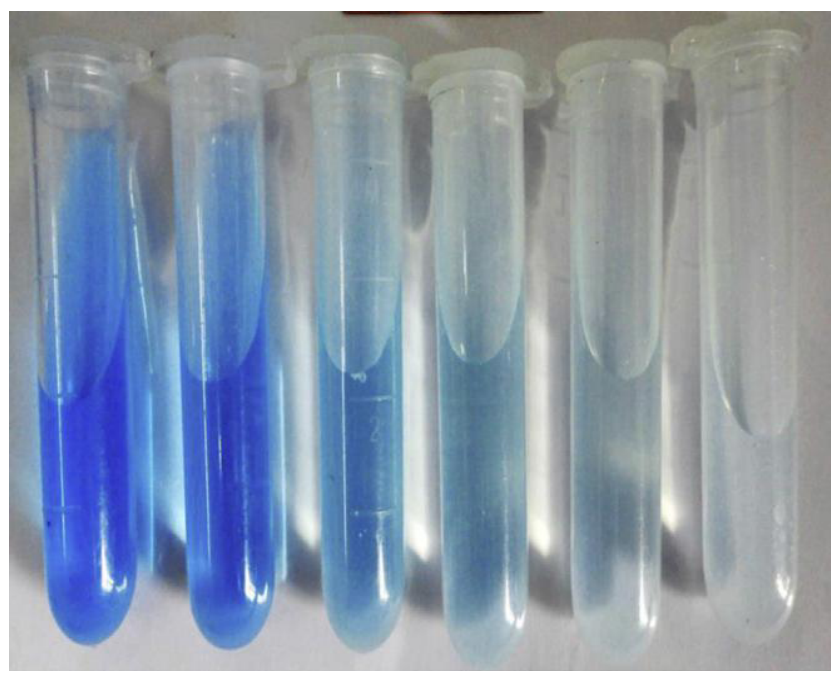

Fig. 3. Photocatalytic effect of the self-cleaning concrete on the MB solution with the exposing time [8]

Depollution testing (NOx Oxidation test). A NOx oxidation test was conducted to evaluate depollution effects of the materials. Jun Chen et al. [19] used a stirred flow reactor to measure the photodegradation of organic compounds on the photocatalytic material surface regarding the degradation of VOCs. Photocatalytic activity of pure samples of $\mathrm{TiO}_{2}$ was observed three to ten times greater than the cementitious sample with $3 \%$ catalyst that was prepared.

The same test was reported by P. Krishnan et al. [15] but differ from machine that used to test photocatalytic degradation of gaseous pollutant. In these researches, a continuous flow reactor was modified and used for photocatalytic NOx removal test, while the concentration of NOx concentration was measured by a Chemiluminescence NOx analyzer. On the other hand, the photocatalytic degradation efficiency was not increased even dosage of $\mathrm{TiO}_{2}$ increased from $2 \%$ to $4 \%$ in the mortar.

\section{Summary}

The current knowledge shows that the influence of adding photocatalyst in the cementitious material is essential for enhances the mechanical properties of self-cleaning concrete. As a conclusion, nanoparticles of photocatalyst are a potential material to be as filler or replacing part of cement in order to improve the performances of self-cleaning behavior. Based on this review, further study on development of geopolymer concrete of self-cleaning applications can be conducted. 


\section{References}

1. M.B. Karakoc, F. Kantarci, I. Turkmen, R. Demirboga, M.M. Maras, M.U. Toprak, Renewable Energy Research and Applications (ICRERA), 2013 International Conference on IEEE, (2013)

2. Sharma, K. Sanjay, Himmi Gupta, Development of Paver Block by Using Foundry Sand Based Geopolymer Concrete (2015).

3. Banerjee, Swagata, Dionysios D. Dionysiou, Suresh C. Pillai, Appl. Catal. B-Environ., 176, 396 (2015)

4. A. Khitab, M. Alam, H. Riaz, S. Rauf, Adv. Life Sci., 1, 47 (2014)

5. R. Khataee, V. Heydari, L. Moradkhannejhad, M. Safarpour, S. W. Joo, J. Nanosci. Nanotechnol, 13, 5109(2013)

6. Dahlan, Dahyunir., Effect of Aging Time on the Synthesis of Fe-doped TiO2 Thin Films by Spin Coating Method (2016).

7. S. Rao, P. Silva, J. De Brito, Constr. Build. Mater, 96, 508(2015)

8. Shen, Weiguo, J. Clean Prod., 82, 762(2015)

9. M. Janus, J. Zatorska, A. Czyzewski, K. Bubacz, E. Kusiak Nejman, A. Morawski, Appl. Surf. Sci, 330, 200 (2015)

10. Khushwaha, A., Rachit Saxena, Shilpa Pal., J. Civ. Eng. Manag, 2, 482(2015)

11. A.H. Aissa, E. Puzenat, A. Plassais, J.M. Herrmann, C. Haehnel, C. Guillard, Appl. Catal. B-Environ, 107, 1(2011)

12. D. Feng, N. Xie, C. Gong, Z. Leng, H. Xiao, H. Li, X. Shi, Ind. Eng. Chem. Res., 52, 11575(2013)

13. P. Duan, C. Yan, W. Luo, W. Zhou, Constr. Build. Mater., 106, 115 (2016)

14. Mohd Mustafa Al Bakri, Abdullah, Geopolymerization technology for soil stabilization application (2014).

15. P. Krishnan, M.H. Zhang, L. Yu, H. Feng, Constr. Build. Mater, 44, 309 (2013).

16. H. Li, H.G. Xiao, J. Yuan, J. Ou, Compos. Part B-Eng, 35, 185 (2004)

17. Bastos, Guillermo, Materials, 9, 972(2016)

18. E. Jimenez Relinque, J.R. Rodriguez Garcia, A. Castillo, M., Castellote, Cement Concrete Res., 71, 124 (2015)

19. Chen, Jun, Chi-sun Poon, Build. Environ., 44, 1899 (2009) 